\title{
Uebersicht der Resultate.
}

\begin{tabular}{|c|c|c|c|c|c|}
\hline \multicolumn{3}{|c|}{ Erster Gang. } & \multicolumn{3}{|c|}{ Zweiter Gang. } \\
\hline & onnen. & Remis. & Ge & onnen. & Remis \\
\hline Wyvill & 2 & & Anderssen & 4 & \\
\hline Lowe & 0 & 0 & szén & 2 & $\mathbf{0}$ \\
\hline Capt. Kennedy & 2 & & i Tyvill & 4 & \\
\hline Mayet & 0 & () & Capt. Kennedy & 3 & 1 \\
\hline Williams & 2 & & Staunton & 4 & \\
\hline Lowenthal & 1 & 0 & Horwitz & 2 & 1 \\
\hline staunton & 2 & & Williams & 4 & \\
\hline Brodie & 0 & 0 & Mucklow & $\mathbf{0}$ & 0 \\
\hline Anderssen & 2 & & & & \\
\hline Zleseritzky & 0 & 1 & & & \\
\hline Sxén & 2 & & & & \\
\hline \{ Newham & 0 & 0 & & & \\
\hline f Horwitz & 2 & & & & \\
\hline Bird & 1 & 1 & & & \\
\hline I Hucklow & 2 & 0 & & & \\
\hline \{ D. S. Kenned\} & 0 & 0 & & & \\
\hline
\end{tabular}

\begin{tabular}{|c|c|c|c|c|c|}
\hline \multicolumn{3}{|c|}{ Dritler Gang. } & \multicolumn{3}{|c|}{ Vierter Gang. } \\
\hline Ge & onnen. & Remis. & Gev & onne & Remis. \\
\hline f Anderssen & 4 & & Anderssen & 4 & \\
\hline Staunton & 1 & 0 & Wyvill & 2 & 1 \\
\hline Wyvill & 4 & & I Williams & 4 & \\
\hline Williams & 3 & 0 & staunton & 3 & 1 \\
\hline sudn & 4 & & | Szén & 4 & \\
\hline Horwitz & 0 & 0 & Capt. Kennedy & 0 & 1 \\
\hline $\begin{array}{l}\text { Capt. Rennedy } \\
\text { Mucklow }\end{array}$ & $\begin{array}{l}4 \\
0\end{array}$ & 0 & $\left\{\begin{array}{l}\text { Eorwitz } \\
\text { Mucklow }\end{array}\right\}$ Kam's & $\begin{array}{l}\text { egen } \\
\text { nicht }\end{array}$ & $\begin{array}{l}\text { heit Muck- } \\
\text { de. }\end{array}$ \\
\hline
\end{tabular}

